\title{
The Importance of Insects in Australian Aboriginal Society: A Dictionary Survey
}

Aung $\mathrm{Si}^{1^{*}}$ and Myfany Turpin ${ }^{2}$

Author Addresses: ${ }^{1}$ School of Languages and Linguistics, University of Melbourne, Babel (Building 139), Parkville, VIC 3010, AUS. ${ }^{2}$ Sydney Conservatorium of Music, The University of Sydney, C41, NSW 2006, AUS.

"Corresponding author: aung.si@unimelb.edu.au

Received: May 3, 2015

Volume: 6(1):175-182

Published: September 17, 2015

(C) 2015 Society of Ethnobiology

Abstract: The use of insects by indigenous societies is an understudied topic, but much useful information can be gleaned from field linguists' dictionaries. In this essay, we explore published and draft dictionaries of selected Australian Aboriginal languages to report on the scope of insect use by coastal and desert communities. We found a number of insect orders exploited for food, medicine, and other uses, as well as a clear trend towards more reliance on edible insects among desert communities. The cultural importance of certain groups of insects can be correlated with a proliferation of associated vocabulary. We suggest that such groups may be regarded as cultural keystone taxa.

Keywords: Edible insects, Australian Aboriginal languages, Ethnoentomology, Honeybee, Moth larva, Beetle larva

A neglected area of ethnobiological research is the documentation of people's knowledge and uses of insects (ethnoentomology), despite recent moves by the Food and Agricultural Organization to highlight this key topic (Van Huis et al. 2013). Insects are an important source of food in many cultures. They are also used for textiles (e.g., silkworms), pharmaceuticals, food coloring, musical instruments, and as pets; many are regarded as objects of beauty and are celebrated in poetry and song (Van Huis et al. 2013:6). Unfortunately, in spite of decades of intense linguistic and anthropological research and documentation in Indigenous Australian societies, relatively little is known about the role of insects in those societies (Yen 2005).

The most familiar use of insects in Australia is as a source of food, as exemplified by the witchetty grub (Endoxyla leucomochla Turner Lepidoptera: Cossidae), ${ }^{1}$ the honey from native bees (Tetragonula spp. Michener Hymenoptera: Apidae, Austroplebeia spp. Friese Hymenoptera: Apidae) and honey-ants (Camponotus inflatus Lubbock Hymenoptera: Formicidae). Throughout much of Australia, various insect larvae have comprised a significant part of traditional diets through time (Tindale 1953, 1966; Yen 2005:381). Concerning the Pitjantjatjara of central Australia, Tindale (1953:59) writes that "women and children spend much time digging for [witchetty grubs] and a healthy baby seems often to have one dangling from its mouth in much the same way that one of our children would be satisfied with a comforter." The seminal work on the Indigenous people of the Australian Alps, The Moth Hunters (Flood 1980), pays tribute to the vital role the Bogong moth (Agrotis infusa Boisduval Lepidoptera: Noctuidae) plays as sustenance for the Alpine people. These charismatic species are, however, but a few of the insects that were traditionally eaten. Despite the fact that Australia boasts the highest diversity of root dwelling Lepidoptera consumed worldwide, Indigenous Australian uses and categorization of these insects remain largely absent from research on entomophagy (Van Huis et al. 2013:xiii, 20).

Indigenous Australians also use insects for purposes other than food. Recent linguistic and ethnobiological research reveals additional uses of insects as bait, medicines, poisons, adornments, toys, and technology, while also serving as indicators of meteorological and other ecological phenomena (Turpin et al. 2013). Across Australia, insects feature in mythology, place names, personal names, and songs, including the large-scale 'increase ceremonies' that were once regularly performed to assist the proliferation of certain species (Hercus 1992). In some regions, the collection and preparation of certain insects was shrouded in mystery and prohibitions (Hercus 1989). These specialized and revered cultural practices allude to the economic significance of certain insects in traditional societies. 


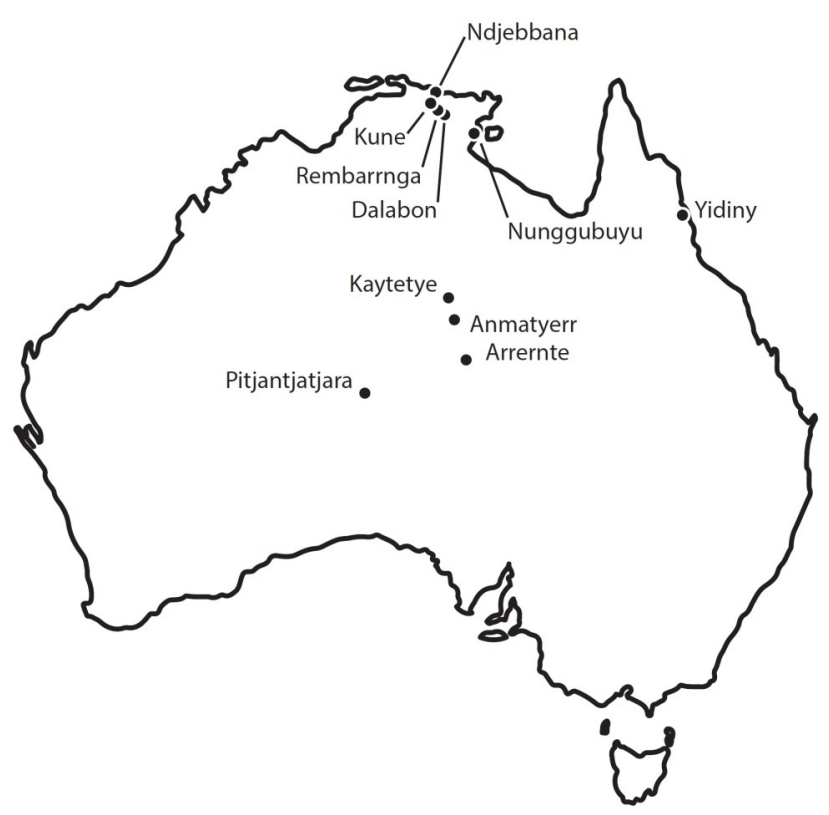

Figure 1. Approximate location of Aboriginal languages referred to in this paper.

In this essay, we survey dictionaries of Indigenous Australian languages to present an overview of patterns of insect use in communities from different parts of the continent. Findings from relevant nonlexicographic publications are also discussed. Dictionaries are widely regarded by linguists and Aboriginal communities as repositories of not just linguistic, but also cultural information. Lifestyle change, language loss, and the introduction of mainstream 'city' foods have conspired to drastically reduce entomophagy and the knowledge of traditional insect uses among Indigenous Australian communities. It is fair to say that in the not-too-distant future, dictionary entries may be the only indication that certain insects were once consumed or used in other ways. We hope that this essay will encourage field linguists, anthropologists, and ethnobiologists to pay more attention to documenting the insect knowledge of Indigenous communities.

\section{The Australian Languages Investigated}

This paper investigates the domain of insects in the central Australian (desert) languages Kaytetye (Turpin and Ross 2012), Arrernte (Breen 2000), and Anmatyerr (Green 2010). Northern Australian (coastal and floodplain) languages referred to in this paper include Bininj-Gunwok (Garde, n. d.) and its Kune dialect, Rembarrnga (Saulwick 2003), Dalabon (Evans et al. 2004), Ndjebbana (Green et al. 2007), Yidiny (Dixon 1991), and Nunggubuyu (Heath 1981) (Figure 1). The first four languages occur in close proximity to each other in west Arnhem Land, while Yidiny is spoken in Cape York and Nunggubuyu in southeastern Arnhem Land.

The primary sources of data cited in this essay are field dictionaries of the languages named above. The languages were mainly chosen from parts of Australia where the authors had carried out fieldwork. The dictionaries cited above represent, in most cases, the only dictionary ever produced of the respective languages. All invertebrate-related lexemes from each dictionary were first collated into a spreadsheet, along with definitions, anthropological notes, and example sentences in the target language (with translations). The entries were arranged according to broad taxon in order to detect general patterns in naming patterns and cultural significance.

\section{Role of Insects in Australian Aboriginal Cultures} The traditional Aboriginal diet consists of many different types of insects. Yen (2005) identifies the following groups of insects (or their products) that were known to be eaten by Aboriginal people:

1) Isoptera (termites)

2) Hemiptera (scale insects)

3) Hymenoptera (ants and bees)

4) Orthoptera (Grasshoppers, crickets, locusts)

5) Coleoptera (beetles)

6) Lepidoptera (moths)

Some insects or insect derived foods are still highly prized today, such as the honey-ant, lerp produced by a type of psyllid on the Normanton box tree, honey, and witchetty grubs. Some dictionaries of Arnhem Land languages name up to six honeybee types, although many fail to provide precise scientific identifications. An exception is Garde's (n. d.) Bininj Gunwok dictionary, which lists the following honeybee types: rdiwarrah (Tetragonula hockingsi Cockerell Hymenoptera: Apidae), yurdu (Austroplebeia symei Rayment Hymenoptera: Apidae), modjarnh (T. mellipes Friese Hymenoptera: Apidae), and nabadyalke (Tetragonula sp.). Some desert languages distinguish cold weather honey, with its crystalized lumps, from honey obtained in warmer months (Turpin \& Ross 2012:50). Many name up to four different parts of the hive (Green 2010). In Kaytetye, the word ilperalke 'native bee, honey' is also a 'sweet food' classifier that 
can go before the word for any type of sweet food (Turpin \& Ross 2012:392). Most commonly, the insects themselves are a source of food, as in the case of witchetty grubs. Dictionaries of Australian Indigenous languages typically have at least one lexeme glossed as 'witchetty grub' (Rem. mork; Nun. guman mana, ngadan mana; Dal. doluk). Whether these represent a single or multiple species remains to be determined, due to a lack of scientific identification. Desert languages such as Kaytetye and Anmatyerr have an abundance of terms that label edible insect larvae (this is not the case for the languages of Arnhem Land), with the dictionary of the former containing some 25 different names for edible lepidopteran and coleopteran insect larvae (Turpin and Ross 2012). Most of these larvae have yet to be identified for an important practical reason: Kaytetye folk nomenclature focuses solely on the larval forms (and so Kaytetye speakers are only able to identify and name these forms), whereas formal scientific identification requires the adults of these species to be collected. The folk classification of honeybees and edible insect larvae is an interesting topic of research that has not been properly investigated in Australian languages.

Insects and their products can be used as medicines, and we find that native honey bee larvae can be eaten to alleviate cold symptoms (Turpin and Ross 2012:100) and used as a medicine for itchy skin and sores (Green 2010:52). Ant and termite eggs (Rem: jappuh) and even the hardened earth of the termite mound (Kay, Arr: ngkwepeye) can be consumed if one is feeling weak and shaky (Dobson 2007). Yidiny people recommend squeezing a handful of green tree ants (Yid: jilibura) and drinking the resulting juice mixed with water and the ash of certain trees as a cure for headaches (Dixon 1991). A flu remedy that makes use of green tree ants (Dal: bodbarng) has also been reported from as far away as east Arnhem Land, among the Dalabon people.

Across Australia we find insects used as bait, such as the mole cricket (Gryllotalpidae) in Arrernte (Breen 2000) and various unspecified worms (probably not insects) in Yidiny (Dixon 1991). The processionary caterpillar (juveniles of the bag-shelter moth Ochrogaster lunifer Herrich-Schaffer Lepidoptera: Thaumetopoeidae) used to be spread out, by Kaytetye people, in the nests of Australian bustards (Ardeotis australis J. E. Gray Otididae), making them easier to catch (Turpin and Ross 2012:378). As adhesives, we find that the resin from ant nests is used by many Aboriginal people in manufacturing implements such as spear throwers. Another material commonly used for this purpose, as well as in spears and didgeridoos, is the wax of certain types of native honey bee, such as the ground dwelling bee len in Rembarrnga. The ant-lion (Myrmeleontidae) is used as a toy in central Australia (Turpin and Green 2014), as it is in some other parts of the world (Van Huis 1996).

Another role that invertebrates play is as indicators of events and resource availability. Particular insect behaviors or presence can indicate the availability of some other species. For example, stridulation by various Kaytetye and Anmatyerr beetles (Cerambycidae) is said to indicate the availability of yams and different types of edible grass seeds (Turpin 2013:509). In Arrernte, the length of the train of the processionary caterpillar is used to predict the severity of seasons (Turpin et al. 2013:25). Particular insects are also recognized as favored foods of certain larger animals and are regarded as indicators of the health and presence of yet other species. For example, Kaytetye people regard witchetty grubs as the favored food of the bilby (Macrotis lagotis Reid Thylacomyidae). This marsupial is believed to have a keen sense of hearing, enabling it to hear witchetty grubs chewing wood in the roots below, and so its telltale scratching is a sign that root-dwelling larvae are mature and rising to the surface. In Arnhem Land, the chirping of certain insects can be an indication of the availability of other kinds of food. Cicadas (Rem: dinadinab) can signal that green plums are ripe and can be gathered, and katydids (Rem: jalna) tell people that cheeky yams are ready to be dug up. The loud buzzing of blowflies (Rem: worrorlorl) is said to be a sign that there is a 'devil' or evil spirit nearby, as is the nighttime sound of a cricket (Kay: anakapeltherreye) to Kaytetye people.

\section{Cultural and Regional Differences}

A comparison of the invertebrate-related entries in dictionaries of Australian languages reveals a trend towards a greater number of lexemes related to edible insects in the languages of the arid inland region. While numerous insects are named in the dictionaries of coastal languages from northern Australia, few entries explicitly mention that the insects they describe are eaten. As mentioned above, this contrasts with desert languages where numerous edible insect larvae are given unique names. Many of the insects named in the northern languages are regarded as dangerous or nuisances. Not surprisingly, it also appears that people 


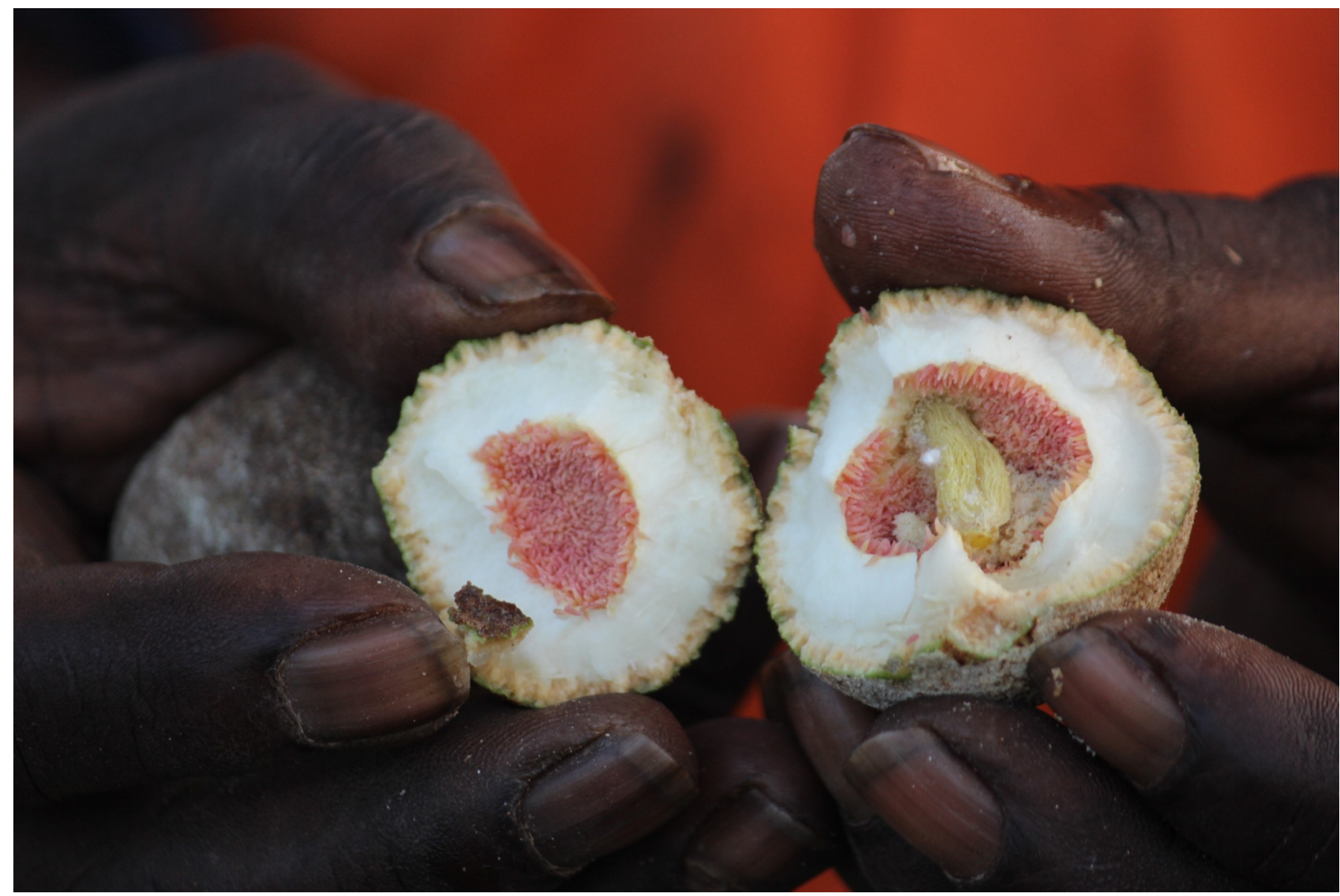

Figure 2. The gall formed by a coccoid insect (poss. Cystococcus pomiformis), showing the large, featureless insect inside the right half and eggs lining the inner surfaces of both halves. Photo by Aung Si.

from coastal areas favor the consumption of marine invertebrates (such as cockles, snails, oysters, and crabs), judging from the large number of lexemes that are used to name this diverse group of organisms. In the more arid parts of Australia, edible insects traditionally occupied this culinary niche. An exception to this trend in the dictionaries examined so far appears to be the Yidiny people of Cape York who, in addition to their many words for edible marine species, also have numerous words for edible grubs and grub life stages (Dixon 1991).

The languages of Arnhem Land do possess the occasional word for an edible insect. The dictionary of coastal Nunggubuyu (spoken by a coastal community in south eastern Arnhem Land) lists six words for insect larvae; although none of the entries explicitly state that they are edible, two words are glossed as 'witchetty grub' in English, implying that at least these organisms might be eaten by Nunggubuyu speakers
(Heath 1981). In the slightly inland Kune dialect of Bininj Gunwok (eastern Arnhem Land), the word for an edible wood dwelling larvae is dolek, and its counterpart in the neighbouring language Rembarrnga (also inland) is morh. A type of edible larvae that lives in 'ant beds' or termite mounds is also named in both languages (Kun. kurndi, Rem. yarnung, mambub). The coastal community of Ndjebbana speakers (west Arnhem Land) recognize two kinds of edible insect larvae, one that lives in wood (Ndj. warrángala) and one that is found in ant beds (Ndj. ngúkarda).

Although the various communities of West Arnhem Land share many cultural and linguistic traits, there is anecdotal evidence of the existence of differences in what is or is not considered edible. The following example, though dealing with a non-insect invertebrate, is illustrative of the general phenomenon. The 'mangrove worms' (Bivalvia) Bankia australis (Calman Teredinidae) and Bactronophorus thoracites 
(Gould Teredinidae) are well known to the people of Arnhem Land (and likely many other coastal areas of Australia) as a food source and are particularly important to the Ndjebbana-speaking Gunibidji people in and around the town of Maningrida. Ndjebbana has two words for 'mangrove worm', namely béwa 'cheeky (i.e. bitter) mangrove worm' and kangódjbaya 'sweet mangrove worm', corresponding to the two biological species named above. The 'sweet mangrove worm' is highly prized, and is said to have medicinal properties, as described in the following excerpt from the draft Ndjebbana dictionary:

This species is regarded as extremely wholesome. When the worms are taken from live wood, the red-colored wood shavings inside the worm's siphons are eaten. When the worms are taken from dead wood, the contents of the siphons are black and silty, like mangrove mud. In this case the contents are squeezed out before the worm is eaten. The worms can be eaten raw, straight from the wood... Salty liquid also drips from the worms themselves. The worms together with this liquid are called "soup" by Aboriginal people. The juice or "soup" is a prized part of the mangrove worm meal. It may be briefly heated on the fire before eating. This "soup" is the Aboriginal cultural equivalent of chicken soup: wholesome and nourishing food at any time, but particularly good for invalids, the elderly, and anyone who needs easily digestible sustenance. It is also given to new mothers after childbirth to help bring in their breast milk. It is so effective for this purpose, that even the European midwives at the Maningrida Community Health Centre prescribe it for new Aboriginal mothers (Green et al. 2007).

A Bininj Kun-wok term for 'mangrove worm' exists (djirdabbadj, from the Kuninjku dialect; Garde, n.d.), but this species would be absent from the traditional ranges of more inland dialects such as Kune and Mayali. It is perhaps not surprising then, that Kune speakers do not consider 'mangrove worms' to be highly desirable food items.

The classification of insects also varies between communities. One example is the coccid insect Cystococcus pomiformis (Froggatt Hemiptera: Coccidae), which lives on the desert bloodwood Corymbia opaca (K.D.Hill \& L.A.S.Johnson Myrtaceae) in central
Australia. A similar insect species occurs in Arnhem Land on another bloodwood, but the taxonomic identities of the northern species are as yet unknown. The insect induces the host tree to form large, spherical woody galls colloquially known as bush coconut' in English. These are harvested and split open and the sap-filled insect and any eggs adhering to the inner wall of the gall are scraped off and eaten (Figure 2). In Central Australia the white lining of the gall (Kay: kwerlperlpe; Arr: arrkirlpangkwerle) is also eaten and classified as a plant food, while the insect (Kay: kathipe, Arr: angure) is classified as kayte 'edible insect larvae'. The Kune word for the gall is dorddord and there is no distinct term for the insect or the eggs inside the gall (Aung Si, pers. obs.). The word dorddord is also a generic term for Eucalyptus trees that bear woody gum nuts or seed capsules (Garde n.d.). Dorddord is categorized as a plant food, manme, by Kune speakers. Manme is also a generic term for 'food' in Kune. However, in relation to dorddord, it is clear that its meaning is the more specific 'plant food'. Kune speakers therefore consider dorddord to be a plant product - this is in keeping with the observation that insect foods are less frequently consumed in this community than in desert communities. Curiously, though, the clear liquid contained inside the body of the coccid inhabitant of the gall is labelled with words for body fluids rather than with a more neutral substance like 'water': mpwe 'urine' in Kaytetye (Turpin and Ross 2004) and djikkano 'milk' in Kune (Aung Si, pers. obs.). In Dalabon, a language spoken to the south-east of Kune territory, speakers do indeed call the edible insides of the gall 'eggs' (Dal: dabuno) possibly in recognition of their insect origins (Evans et al. 2004).

\section{Insects as Cultural Keystone Species}

Our survey of Australian language dictionaries indicates that some edible insects may be considered cultural keystone taxa for certain Aboriginal societies (see also Yen 2010). Garibaldi and Turner (2004:4) define these as "species that shape in a major way the cultural identity of a people, as reflected in the fundamental roles these species have in diet, materials, medicine, and/or spiritual practices." In Aboriginal Australia, cultural keystone taxa (or, more accurately in this case, ethnotaxa) make up a considerable part of the diet and are celebrated in creation stories, ceremonial songs, and designs, as well as in personal and place names. Among the insects, these are frequently honey-ants (C. inflatus), native honeybees, and various 
types of edible insect larvae, such as E. leucomochla. The Mewal songline of the Marrangu clan of northcentral Arnhem Land prominently figures the honeybee as the companion of an important spirit figure; honey and honeybees also play an important role in the funeral ceremony of this clan (Elliott 1991). Honeybees also feature in the creation stories, totems, songs, and rock art of central Australia (Moyle 1986). Finally, Bogong moths are an important food source not only for the people of the Australian Alps, but also critically endangered mammal species such as the Mountain pygmy possum (Burramys parvus Broom Burramyidae) (Mansergh and Broom 1994).

In central Australia, the witchetty grub is a cultural keystone species, being the preferred food out of some 25 uniquely named edible insect larvae. Tindale (1953:59) observed their prominent role in the Central Australian Aboriginal diet and the efficiency by which they could be obtained. Both Pitjantjatjara and Arrernte people perform ceremonies to promote the abundance of these insects, as well as other types of edible insect larvae (Gibson 2013:71; Mulvaney et al. 1997; Tindale 1953:59). The performance of these songs not only honor these species but are thought to play a role in making them more abundant and accessible. In turn, the ever present ancestral beings of these species are known to give songs to people, as in the case of a bull ant spirit (Myrmecia nigriceps Mayr Hymenoptera: Formicidae) giving a ceremonial song to a Kaytetye woman (Turpin and Ross 2004). Various types of edible insect larvae also appear in the creation stories of the Wangkangurru people of the Lake Eyre basin (Hercus 1989, 1992).

Recently, it has been proposed that large, frequently hunted marine vertebrates such as turtles and dugong be regarded as cultural keystone species for Torres Strait Islander communities who live off the northern tip of Queensland, Australia (Butler et al. 2012). These flagship species, it is suggested, can help foster cooperation between government agencies and Indigenous peoples in developing and implementing fisheries management policies. Lesser known insect species also have a claim to cultural keystone status, as they too have the potential to inform land management practices and foster cross-cultural engagement.

We find a correlation between cultural keystone taxa (or ethnotaxa) and ethnotaxa that have a disproportionately large number of unique terms. Both the witchetty grub and native bee have much specialized vocabularies, some of which makes its way into personal and place names through mythological affiliation. There are specific terms for bee eggs, excretions, hives, and parts of the hive. In contrast, there is only one word for 'stick insect' and no unique words associated with the lifecycle of stick insects. We might say that linguistic diversity surrounding an ethnotaxon suggests cultural keystone status. We find bees to be a cultural keystone taxon in both the coastal and inland regions; and edible lepidopteran and coleopteran larvae in the latter region.

\section{Conclusion}

While there have been few focused studies on the uses of insects in Australian Aboriginal societies, our survey of linguists' field dictionaries reveals that much useful, culturally and ethnobiologically significant information lies hidden within the pages of these publications. Northern Australian and Central Desert languages have numerous words for insects that are eaten, used as medicine, or that indicate important phenomena in the immediate environment. However, there are significant geographical differences, with a general trend towards higher levels of insect consumption in desert communities. Attitudinal differences towards the palatability of certain insect species need to be kept in mind when generalizing about Indigenous culinary practices, even in the case of geographically contiguous communities. Our survey also reveals that greater efforts need to be made by linguists in the scientific identification of culturally important insects; this is particularly true of insects such as edible Lepidoptera and Coleoptera and native honeybees, which may be considered cultural keystone species.

\section{Declarations}

Permissions: University of Sydney Human Research Ethics approval (2015/081), University of Queensland Human Ethics Committee (Approval 2006000385), Northern Land Council entry and research permit (47331), and University of Melbourne Human Ethics (Approval 1340550).

Sources of Funding: Australian Research Council, Australian Institute of Aboriginal and Torres Strait Islander Studies, and Endangered Languages Documentation Program, University of Melbourne.

Conflicts of Interest: None declared. 


\section{References Cited}

Butler, J. R. A., A. Tawake, T. Skewes, L. Tawake and V. McGrath. 2012. Integrating Traditional Ecological Knowledge and Fisheries Management in the Torres Strait, Australia: The Catalytic Role of Turtles and Dugong as Cultural Keystone Species. Ecology and Society 17:34-52.

Breen, G. 2000. Introductory dictionary of Western Arrernte. IAD Press, Alice Springs, Northern Territory.

Dixon, R. M. W. 1991. Words of our Country. University of Queensland Press, Brisbane.

Dobson, V. P. 2007. Arelhe-Kenhe Merrethene: Arrernte Traditional Healing. Alice Springs, Northern Territory, IAD Press.

Elliott, C. 1991. 'Mewal is Merri's Name': Form and Ambiguity in Marrangu Cosmology, North Central Arnhem Land. Unpublished Master's Thesis, Faculty of Arts, Australian National University.

Evans, N., F. Merlan and M. Tukumba. 2004. A First Dictionary of Dalabon (Ngalkbon). Maningrida Arts and Culture, Maningrida.

Flood, J. 1980. The Moth Hunters: Aboriginal Prehistory of the Australian Alps. Australian Institute of Aboriginal Studies, Canberra.

Garde, M. n.d. Bininj Gunwok Pan-dialectal Dictionary. Unpublished electronic file.

Garibaldi, A. and N. Turner. 2004. Cultural Keystone Species: Implications for Ecological Conservation and Restoration. Ecology and Society 9:1. Available at: http://www.ecologyandsociety.org/vol9/iss3/ art1/. Accessed on January 04, 2015.

Gibson, J. 2013. Addressing the Arrernte: FJ Gillen's 1896 Engwura speech. Australian Aboriginal Studies 1:57-72.

Green, Jenny. 2010. Central and Eastern Anmatyerr to English dictionary. Institute for Aboriginal Development Press, Alice Springs.

Green, R., G. McKay, C. Coleman and G. Wightman. 2007. Draft Ndjébbana Dictionary, compiled by Rebecca Green with linguistic contributions from Graham McKay and Carolyn Coleman, and scientific contributions from Glenn Wightman. NT Department of Education, unpublished.
Heath, J. 1981. Nunggubuyu Dictionary. Australian Institute of Aboriginal Studies, Canberra, Australian Capital Territory.

Hercus, L. 1989. Preparing Grass Witchetty Grubs. Records of the South Australian Museum 23:51-57.

Hercus, L. 1992. Glimpses of the Karangura. Records of the South Australian Museum 25:139-159.

Mansergh, I. M. and L. S. Broome. 1994. The Mountain Pygmy-possum of the Australian Alps. University of New South Wales Press, Sydney.

Moyle, R. 1986. Alyawarra Music. Songs and Society in a Central Australian Community. Australian Institute of Aboriginal Studies, Canberra.

Mulvaney, J., H. Morphy and A. Petch, eds. 1997. My Dear Spencer: The Letters of F.J. Gillen to Baldwin Spencer. Hyland House, Melbourne, Victoria.

Saulwick, A. 2003. Rembarrnga Dictionary. Maningrida Arts and Culture, Maningrida, Northern Territory.

Tindale, N. B. 1953. On some Australian Cossidae Including the Moth of the Witjuti (Witchetty) Grub. Transactions of the Royal Society of South Australia 76:56-65.

Tindale, N. B. 1966. Insects as Food for the Australian Aborigines. Australian Natural History 15:179183.

Turpin, M. 2013. Semantic Extension in Kaytetye Flora and Fauna Terms. Austraian Journal of Linguistics 33:488-518.

Turpin, M., V. P. Dobson, M. K. Turner and A. N. Ross. 2013. The Spotted Nightjar Calls when Dingo Pups are Born: Ecological and Social Indicators in Central Australia. Journal of Ethnobiology 33:7-32.

Turpin, M. and J. Green. 2014. 'If You Go Down to the Soak Today...' an Arandic children's game. Anthropological Linguistics 55:358-394.

Turpin, M. and A. Ross. 2012. Kaytetye to English Dictionary. IAD Press, Alice Springs, Northern Territory.

Van Huis, A. 1996. The traditional use of arthropods in sub-Saharan Africa. Proceedings of the Section Experimental and Applied Entomology of the Netherlands Entomological Society 7:3-20. 


\section{Et EthNobiolocy Letters $\quad$ Perspectives}

Van Huis, A., K. van Itterbeeck, H. Klunder, E. Mertens, A. Halloran, G. Muir and P. Vantomme. 2013. Edible Insects: Future Prospects for Food and Feed Security. Food and Agricultural Orginization of the United Nations, Rome.

Yen, A. 2005. Insects and Other Invertebrate Foods of the Australian Aborigines. In Ecological Implications of Minilivestock: Potential of Insects, Rodents, Frogs and Snails, edited by M. G. Paoletti, pp. 367388. Science Publishers, New Hampshire.

Yen, A. 2010. Edible Insects and Other Invertebrates in Australia: Future Prospects. In Forest Insects as Food: Humans Bite Back, Proceedings of a Workshop on Asia-Pacific Resources and their Potential for Development, edited by P. B. Durst, D. V. Johnson, R. L. Leslie and K. Shono, pp. 65-84. FAO Regional Office for Asia and the Pacific, Bangkok.

\section{Biosketches}

Aung Si is a biologist and linguist at the University of Melbourne. He works in India, northern Australia and Myanmar.

Myfany Turpin is a linguist and ethnomusicologist at the University of Sydney, working on Aboriginal languages of central Australia.

\section{Notes}

${ }^{1}$ The term 'witchetty' probably comes from the South Australian language Arabana, where witjuti refers to a type of Acacia. Tindale (1953: 59) used the term 'witchetty grub' for the edible grub found in Acacia ligulata Benth. Leguminosae. The species was originally described by Turner (1915) as the cossid moth Xyleutes lencomochla; it is now called Endoxyla lencomocbla. 